\title{
OS TERRITÓRIOS DE ESPERA E O FLUXO RECENTE DE MIGRANTES CLANDESTINOS NA EUROPA. O CASO PARTICULAR DO CAMPO JUNGLE, EM CALAIS (FRANÇA)
}

João Luís J. FERNANDES

Faculdade de Letras (Universidade de Coimbra)/CEIS20/CEGOT

jfernandes@fl.uc.pt

\begin{abstract}
Resumo
A Europa foi destino de um fluxo de migrantes, na procura do estatuto de refugiado, que teve a sua expressão máxima no verão de 2015. O atravessamento do Mediterrâneo e o movimento em direção ao norte do continente, levou ao aparecimento de um conjunto diversificado de espaços que procuraram travar essas deslocações. Nesses territórios de paragem e espera, a insegurança, as tensões e a violência são riscos reais. Uma Europa que promove os valores da hospitalidade e dos direitos humanos deve olhar para essa cartografia de potencial conflitualidade.
\end{abstract}

Palavras chave: Territórios de Espera, Migrantes, Refugiados, Europa, Calais

\begin{abstract}
In the summer of 2015, a high flow of migrants arrived in Europe seeking refugee status. The crossing from North Africa and the movement towards the center of the European continent, led to the appearance of a diverse set of spaces that sought to stop these spatial movements. Life in these territories of waiting and mobility delay is affected by high risks of insecurity, human confrontation and violence. A welcoming Europe in which human rights are defended and promoted should look at this cartography of potencial conflict.
\end{abstract}

keywords: Waiting Territories, Migrants, Refugees, Europe, Calais

\section{Nota introdutória - os territórios de espera enquanto contextos de tensão, potencial insegurança e violência}

Para Alain Musset (2015, 306), "Los fenómenos de movilidad y desplazamiento se afirman como características principales de nuestras sociedades contemporáneas. Sin embargo, lejos de ser fluidos, homogéneos o lineales, estos desplazamientos están marcados por tiempos y momentos, más o menos largos, de espera. Su origen puede ser por razones técnicas, administrativas o 
políticas, y a menudo tales momentos encuentran una traducción espacial: hay territorios que acogen a estas sociedades en situación de espera".

Este geógrafo francês remete-nos para o capital assimétrico de mobilidade espacial. O mundo contemporâneo está marcado pelo movimento e pelas deslocações geográficas. No entanto, diferentes fluxos estão sujeitos a diferentes efeitos de atrito. Os bens materiais e, sobretudo, a informação e o capital financeiro, circulam com alguma fluidez e, dependendo dos casos, com barreiras mínimas. O mesmo não ocorre no que às populações diz respeito. Mesmo nestas, existem diferenças de grupo para grupo e de indivíduo para indivíduo.

No que diz respeito à população que se desloca, na Geografia e noutras áreas afins tem sido dada maior atenção ao movimento e menor ao que ocorre quando esses fluxos são interrompidos.

A mobilidade espacial das populações pode ser travada, em diferentes contextos geográficos, mas também durante períodos variados de tempo. As fronteiras que regulam esses movimentos, nas quais se controlam as identidades e se conferem as mercadorias, constituem, por definição, espaços de uma espera mais ou menos prolongada, consoante as circunstâncias e os atores dessa mobilidade espacial.

Também na circulação rápida, por meios de transporte como os aviões, existem espaços e tempos de espera, seja nas sucessivas barreiras de controlo que um passageiro (e respetiva bagagem) devem atravessar, seja nos momentos de paragem entre as diferentes ligações aéreas, no caso das viagens que impliquem múltiplas escalas.

O mesmo ocorre, noutras circunstâncias, na vida quotidiana das cidades. Os espaços e os tempos de espera nas rodovias durante os usuais engarramentos de trânsito são disso exemplo. Mesmo fluindo sem problemas, a espera pelo momento no qual se ilumina o sinal verde de um semáforo, que autoriza os condutores a avançar, é muitas vezes tensa. Por parte dos peões, a espera pela ocasião certa para atravessamento de uma via pode ser um tempo de ansiedade e precipitação.

Igual desestabilização individual e coletiva poderá ocorrer nos contextos espaço-temporais de espera para entrada ou saída de recintos desportivos ou de eventos culturais e de entretenimento, como concertos musicais. Nestes casos, de modo a reduzir os riscos, quer a arquitetura e a organização estrutural dos edifícios (ou dos recintos ao ar livre), quer os planos de evacuação, devem respeitar regras como a redução dessa espera a um tempo mínimo.

O levantamento de barragens ao movimento e a consequente formação de territórios de espera, tensos e potencialmente violentos, também acontece em contextos de reivindicações de massas e movimentações coletivas. Assim ocorreu em Paris e noutras cidades francesas em novembro de 2018, no denominado "Protesto do Colete Amarelo", que contestava a decisão governamental de aumento dos impostos sobre os combustíveis fósseis. A saída de cerca de 290 mil pessoas para a rua, interrupções compulsivas de estradas e vias urbanas e ameaças ao total bloqueio da capital, definiram uma cartografia temporária, mas conflituosa, de territórios de espera, que coloca em confronto manifestantes, autoridades e cidadãos que apenas pretendem seguir viagem (BARATA, 2018). 
Neste sentido, e seguindo ainda Musset (2015), mas também Vidal e Musset (2015), por espaços de espera devem entender-se as circunstâncias nas quais, numa espacialidade mais ou menos restrita e confinada, se alarga o tempo de interrupção de um fluxo humano. Para estes autores, ainda que existam alguns espaços preparados para essa paragem (por exemplo, as salas de espera numa estação de comboios), em muitos casos essa espécie de suspensão ocorre em espacialidades não preparadas para o efeito.

Para além disso, e prosseguimos com as mesmas referências bibliográficas, esses espaços de espera não são neutros sob o ponto de vista social e geohumano. Pelo contrário, seja numa fronteira de paragem de potenciais imigrantes, seja numa pausa de espera para entrar num avião, estabelecem-se relações interpessoais e desenvolvem-se estratégias de apropriação do espaço, mais ou menos duradouras e/ou precárias, consoante o tempo envolvido.

Os confinamentos espaciais prolongados em resultado de condenações judiciais (em espaços como as prisões ou outros centros de detenção), podem incluir-se neste contexto de sociabilidades e apropriações. Por isso, mais do que espaços, estamos perante territórios de espera, que resultam de dinâmicas muito diversificadas de desterritorialização-reterritorialização, isto é, de perda e recuperação (ainda que parcial) de controlo sobre o território por parte de quem se desloca ou pretende deslocar-se (HAESBAERT, 2004).

Os territórios, enquanto espacialidades que resultam de alguma forma de apropriação (RAFFESTIN, 1980), podem ser construídos quer pelos indivíduos em espera, quer por outros atores que organizam a sua territorialidade em torno dessa paragem, prestando serviços e retirando alguns benefícios desse envolvimento. A esse propósito, Alain Musset (2015) mostra-nos como, nos engarrafamentos de automóveis numa rodovia de Tijuana, no México, um conjunto de vendedores se organiza e se estrutura sob o ponto de vista espacial. Neste estudo de caso, cada grupo tem uma localização específica e apropria-se de um determinado setor da fila de automóveis, usando os tempos de espera dos condutores para comercializar os seus produtos.

Contudo, os territórios de espera podem significar prudência. Os portos de abrigo nas viagens marítimas, as albergarias e as estalagens nas velhas travessias a cavalo, a espera num aeroporto aguardando a passagem da tempestade, os bancos abrigados numa qualquer paragem urbana de espera de um autocarro, todos estes contextos espaço-temporais fazem parte de estratégias de mitigação dos riscos e aumento do conforto e da segurança. Em muitos destes casos, a espera torna a viagem segura e viável.

No entanto, a espera prolongada, indefinida, não planificada e involuntária, pode ser uma territorialidade e um contexto espacial e temporal potencialmente inseguro e violento. A frustração da não chegada do transporte. A espera em espaços mal preparados para o efeito. $A$ incerteza e a falta de garantias no que respeita ao limite da espera, todos estes fatores podem aumentar a tensão e ampliar o potencial de violência.

Por vezes, a espera prolonga-se em contextos de confinamento territorial. Assim ocorreu ao longo da História com múltiplos casos de quarentena. Assim foi em Ellis Island, no final do século $\mathrm{XIX}$, onde os potenciais imigrantes que pretendiam entrar nos EUA eram retidos por tempo indeterminado por razões sanitárias. O mesmo se verificou, nestas geografias higienistas, com a 
paragem e confinamento dos doentes em leprosarias como a ilha de Spinalonga, em Creta, na Grécia (KOTSIOU, MICHALAKI E ANAGNOSTOPOULOU, 2017), ou nos sanatórios montanhosos e serranos, para doentes com tuberculose, em regiões como os Alpes ou, no caso português, a Serra da Estrela e o Caramulo (VELOSO, 2009).

A espera prolongada numa rodovia interrompida, assim como o confinamento territorial de passageiros num aeroporto durante um período de greve ou de intempérie meteorológica, cria contextos espaço-temporais delicados e potencialmente conflituosos, sobretudo se se associarem a grandes massas de condutores/passageiros retidos em espaços delimitados e impedidos de se movimentarem.

Noutro contexto, a retenção espacial e precária da população palestiniana na Faixa de Gaza, constitui um território de espera de potencial agressividade e insegurança, como se demonstra pelos constantes episódios de violência entre esta comunidade confinada e os militares israelitas que vigiam o perímetro muralhado (HASS, 2005; KAJJA, 2008). Nesta territorialidade em espera, assistese também à degradação da qualidade de vida das populações, como se confirma no estudo de Abdel Aziz Mousa Thabet (2017) a propósito das crianças da Palestina e, em particular, desta faixa de território confinado e vigiado a partir do exterior. Como refere Thabet $(2017,7)$, "Palestinian children had been the victims of trauma and violence due to war and conflict and they are at great risk of developing mental health problems such as PTSD, depression, anxiety, hyperactivity, and somatic disorders. Presence of mental health problems were related to severity and continuity of stress and trauma".

Nesta perspetiva, quando a precariedade é grande e os riscos elevados, estes territórios de espera são lugares de instabilidade, ansiedade e infracção de direitos elementares. Tratam-se de traumascapes de sofrimento e demonstração violenta de relações assimétricas de poder (TUMARKIN, 2005).

São muitos os exemplos de cidades e populações sitiadas ao longo da História da Humanidade, espaços urbanos em espera no contexto de conflitos armados (DOWDALL e HORNE, 2018). O cerco a Sarajevo durante a guerra dos Balcãs, na Bósnia, promovido pelas forças sérvias da autoproclamada República Srpska e do Exército Popular Jugoslavo, entre 5 de abril de 1992 e 29 de Fevereiro de 1996, provocou um longo território de espera, humilhação e degradação das condições de sobrevivência das populações. Segundo Ivana Macek (2009), para além da espera coletiva de todo um território urbano, viveram-se contextos conflituosos de espera de serviços e recursos como a água potável, a eletricidade, o gás ou o acesso a voos excecionais assegurados pela Organização das Nações Unidas.

Outro exemplo - uma cidade cercada por forças inimigas e, nesse sentido, um território de espera aguardando a chegada de auxílio que a libertasse desse aprisionamento, foi Leninegrado, a atual Sampetersburgo, durante a II Guerra Mundial, entre 1941 e 1944 (JONES, 2008).

Como refere ainda Watcher $(2018,37)$, "The German decision to besiege rather than conquer Leningrad, and the Soviet decision to hold the city at any cost, resulted in one of the greatest human catastrophes of the Second World War. Estimates are that at least one out of three million civilians2 fell victim to starvation between 8 September 1941 and 27 January 1944; only a minority of these 
civilian casualties were caused by illness, bombing or shelling. Living conditions during the blockade of Leningrad, especially in the first winter under siege, have been compared to living conditions in Nazi concentration camps. Not only the scale of death and deprivation, but also the sense of alienation, exposure and disintegration of social and psychological processes, justify such a comparison."

Este raciocínio pode transportar-nos para os atuais territórios políticos de identidade incerta nas relações internacionais, supostos espaços geográficos soberanos (ou que se pretendem soberanos). Por exemplo, o Kosovo, apesar da declaração da independência ter ocorrido em 2008, apenas foi reconhecido e admitido pela UEFA e pela FIFA, duas instituições associadas à globalização do futebol, em 2016. A Abecásia, a Ossétia do Norte ou a Transnístria, aguardam também uma definição política e um reconhecimento mais alargado no conjunto dos Estados que fazem parte da Organização das Nações Unidas. Nestes territórios de espera, a precariedade e a degradação das condições de vida são um risco elevado que compromete um futuro incerto. Segundo Tomczyk $(2018,53)$, tratam-se de "separatist regions at a standstill" ou, por outras palavras, territórios e populações a viver uma espécie de "life in limbo" (WAAL, 2018, 8) que aumenta a desconfiança e compromete os projetos individuais e coletivos.

Ainda assim, um dos exemplos mais expressivos de um território de espera será um campo de refugiados. Após a desterritorialização, algures numa área de conflitos, os refugiados (ou candidatos à condição de refugiado) ali se reterritorializam, muitas vezes de modo precário, aguardando a retoma do trajeto em direção a um destino final desejável (HAESBAERT, 2004). Em muitos casos, nestes territórios demarcados, essa espera pode prolongar-se por anos, por vezes até por diferentes gerações, tornando a espera um processo que se arrasta lentamente no tempo (AGIER, 2014).

No entanto, nas dinâmicas espaciais da população refugiada, os territórios de espera vão-se (re) configurando em múltiplas etapas desta mobilidade precária, como se discutirá a propósito do fluxo que pressionou as fronteiras europeias, sobretudo no verão de 2015.

\section{Territórios de Espera no âmbito dos fluxos de refugiados na Europa durante o Verão de 2015}

A guerra na Síria e a desintegração do Estado líbio, uma série de outros conflitos não resolvidos em África, mas também os ciclos de pobreza nestes territórios e a conjugação destes fatores com o crime organizado concorreram para o recente aumento da pressão migratória, sobretudo clandestina, sobre o Mediterrâneo e as fronteiras europeias, com especial incidência no verão de 2015 (Figura 1).

De acordo com a ESI- European Stability Initiative (2017), no período entre 2009, antes do início da Primavera Árabe e da eclosão da guerra na Síria, e 2016, terão ocorrido cerca de 2 milhões e 50 mil atravessamentos ilegais nas fronteiras da União Europeia. Desse total, $65 \%$ seguiu a rota do Mediterrâneo Oriental, em direção à Grécia. 32\% seguiu o trajeto do Mediterrâneo Central, que converge para a Itália. Desses mais de 2 milhões de migrantes, 51\% delocaram-se em 2015, ano de especial pressão sobre as costas gregas, correspondendo a 885 mil entradas ilegais. Na Itália, esse valor atingiu os 154 mil migrantes. 


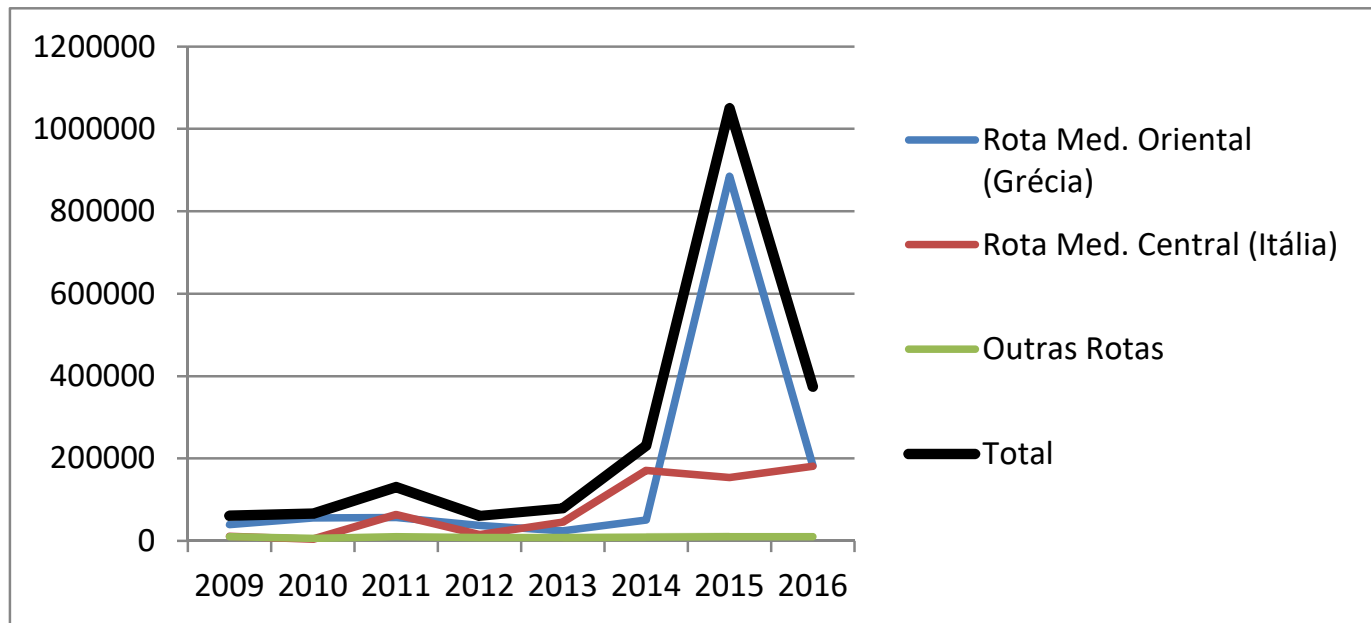

Figura 1 - Fluxo de migrantes ilegais que atravessaram as fronteiras da União Europeia, entre 2009 e 2016, seguindos as rotas do Mediterrâneo e outras (Fonte:ESI, 2017).

Estas estatísticas traduziram-se em diferentes dinâmicas geográficas, nas quais se incluem aqui os referidos territórios de espera, que começam a ser estruturados logo antes da tentativa de entrada da Europa.

No norte de África, as cidades líbias de Tripoli e Zuwarah, as mais próximas das fronteiras europeias, a cerca de 160 milhas marítimas da ilha grega de Lampedusa, são lugares de chegada de múltiplas rotas que, nalguns casos, atravessam o Saara, noutros trazem migrantes desde o Próximo e Médio Oriente, mas também de países como a Somália ou a Eritreia.

Ponto de partida para viagens clandestinas de barco, esta região litoral é o primeiro obstáculo ao prosseguimento dos migrantes que desejam chegar à Europa. Como referem Tinti e Reitano (2018), muitos destes deslocados são vítimas de suborno por parte de redes criminosas e ficam retidos em campos de detenção. Nestes, a espera prolonga-se e a exploração de seres humanos fazse a pretexto do necessário pagamento das dívidas contraídas junto destes grupos de traficantes.

Para Alain Musset (2015), as embarcações precárias que partem para Lampedusa e outros pontos de chegada, podem ser considerados territórios de espera. Neste caso, a espera faz-se em movimento, aguardando a vista de uma costa segura. Também nas embarcações se constroem territórios, pois neste contexto de vulnerabilidade estabelecem-se hierarquias e relações de poder. Como acrescentam Tinti e Reitano (2018), em muitos casos os melhores lugares e o direito ao uso de colete salva-vidas estão reservados aos imigrantes sírios, com maior poder económico. Os deslocados da África subsaariana ocupam os lugares restantes, apenas para completar a lotação do barco.

Uma viagem pela Europa daquela época é um percurso por um conjunto diversificado de espaços de paragem e confinamento de migrantes provenientes deste e de outros corredores de mobilidade. Este efeito de atrito com o qual a Europa se foi protegendo, protelando o avanço destes fluxos, materializou-se na constituição de territórios de espera, alguns efémeros e de rápido desaparecimento, outros mais perenes e duráveis. 
A ilha de Lesbos, também na Grécia, localiza-se a $10 \mathrm{~km}$ da costa turca. Com $1600 \mathrm{~km}^{2}$ de superfície e uma população residente de 86 mil habitantes (38 mil na sua principal cidade, Mytilene), este território insular foi outro dos pontos de entrada procurados por quem seguiu a rota do Mediterrâneo Oriental (JAUHIAINEN, 2017). Chegando a concentrar um número de deslocados $80 \%$ acima das suas capacidades, parte da população migrante ficou retida, por um longo período de espera, em lugares demarcados. Nestes campos (de retenção ou detenção?). Moria foi um dos principais pontos de chegada. Este antigo campo militar rodeado por muros é regulado pelas autoridades gregas, com a presença do ACNUR - Alto Comissariado das Nações Unidas para os Refugiados.

Como nos indicam Polly Pallister-Wilkins (2018) e Lydie Arbogast (2016), Moria é considerado um hotspot de receção de deslocados: "since spring 2015, a new type of detention facility has emerged: hotspots. Established under the auspices of the EU, hotspots focus on the systematic identification and registration of all migrants arriving in 'frontline' countries, i.e. Greece and Italy. Officially presented as "access points" established to respond to the tragic drownings in the Mediterranean and the 'refugee crisis', they have become new detention and filtering camps to "store" people awaiting relocation to another Member State or deportation from the EU" (ARBOGAST, 2016, 26).

Dividido por setores étnicos, em Moria os migrantes alojaram-se em tendas, entretanto substituídas por edifícios mais consistentes mas, ainda assim, precários. Como se refere em Jauhiainen (2017) e em Murray (2018), a ocupação excessiva aumentou a tensão, provocou distúrbios e motins, justificando a presença de forças de segurança, dentro e fora do campo. Após o verão de 2015, chegaram a fixar-se cerca de 20 mil deslocados em Lesbos. Nem Moria nem os restantes campos daquela ilha tinham capacidade para além dos 25\% desse valor (MURRAY, 2018).

Os conflitos, as carências, a ausência de serviços básicos, a má qualidade de vida, doenças mentais, as tentativas de suicídio (alguns consumados), a morte pela exposição a temperaturas extremas, a exploração de seres humanos, foram acontecimentos comuns neste território 'precário' de 'espera', no qual era possível a saída do migrante (que, no entanto, ficava confinado na ilha), mas negado o acesso a pessoas estranhas ao campo (ARBOGAST, 2016; JAUHIAINEN, 2017).

Ainda consultando Jauhiainen (2017), num levantamento efetuado em 2016, apenas $16 \%$ se sentiriam seguros em Moria. Estes valores refletem as caraterísticas deste território de espera: o primeiro centro de acolhimento de migrantes precários nesta ilha, sobretudo deslocados individuais do sexo masculino. Para Jauhiainen $(2017,33)$, perante as indefinições burocráticas em relação ao futuro, neste campo "Life is wasted in seemingly eternal waiting". Ainda para este autor $(2017,41)$, "Most asylum seekers stay in the reception sites in Lesvos for several months. They do not know about their future, including if and when they will be able to settle in the European Union or whether they will have to return to their country of origin. The long waiting process creates problems for asylum seekers, and the authorities are having to deal with these problems".

Como refere Arbogast $(2016,12)$, "Detention of migrants in the EU and elsewhere takes place in a complex and multifaceted environment. Located in ad hoc buildings or pre-existing structures such as prefabs, warehouses, army barracks and prisons, closed camps are mostly surrounded by 
walls, fences or barbed wire. However, the reality of confinement is not limited to these traditional setups. Other so-called "open" centres, most often designed for temporary accommodation of asylum seekers in isolated areas, are also based on confinement: under the guise of 'accommodation' for migrants, they facilitate administrative and social control".

O excesso de migrantes nos campos de contenção de Lesbos levou à ocupação de solos intersticiais daquele território de chegada. Segundo Murray $(2018,87)$, “(...) as tendas espalharam-se pelo centro da cidade de Mytilene, em qualquer espaço relvado ou cheio de entulho disponível, em rotundas e passeios". No entanto, como prova de alguma solidariedade local, Douglas Murray (2018) afirma também que, no inverno de 2016, em resultado de estados de tempo extremos e desconfortáveis, parte da população local abriu as suas casas e garagens para acolher alguns destes migrantes precários.

Estes territórios de espera difusos, distribuídos de modo irregular por vácuos das áreas urbanas, como solos livres debaixo dos viadutos ou de escadarias, espaços em redor das estações do metropolitano, em áreas ajardinadas, praças ou vias de circulação, expuseram estes migrantes nos espaços públicos de cidades como Paris, Atenas ou Roma. Estes acampamentos improvisados transportaram para as ruas de algumas cidades da Europa, imagens que os cidadãos europeus apenas viam à distância, através dos meios de comunicação social.

Em cidades como Paris e outras, à escala da União Europeia, criou-se uma rede legal de lugares de acolhimento, nos quais também aqui a espera por uma decisão burocrática pode ser prolongada. Esses podem ser espaços de controlo estatal. No entanto, dependendo do país, é possível serem também geridos pela iniciativa privada (ARBOGAST; 2016).

Contudo, a atitude de muitos Estados europeus levou também ao reforço securitário das respetivas fronteiras. Este fluxo teve como resposta o levantamento de barreiras materiais para interromper a passagem e proteger a Europa. Já nos anos (19)90 se haviam levantado vedações em Ceuta (em 1993, com 9 km de comprimento) e Melilla (em 1998, com 12 quilómetros), para blindar o enclave espanhol no norte de África.

Com a crise de 2015, levantaram-se outros muros. A Hungria ergueu barreiras nos limites que a separam da Croácia e da Sérvia. À revelia dos Acordos de Schengen, a Áustria reforçou a sua fronteira com a Eslovénia, construíndo um muro e postos de controlo em Spielfeld. O mesmo ocorreu na Grécia, na fronteira com a Turquia, junto à aldeia de Nea Vyssa, onde se construiu uma vedação de $12,5 \mathrm{~km}$, coroada por um reforço suplementar de arame farpado. Também na fronteira entre a Macedónia e o espaço nacional grego se procedeu ao esforço policial e securitário, fazendo da aldeia grega de Idomeni um território de espera e contenção que travou a viagem dos refugiados para norte.

Nesta geografia de muros temporários, impôs-se a lógica do levantamento de barreiras na retaguarda, sempre que o fluxo, a montante, na sua caminhada para o centro da União Europeia, em especial em direção à Alemanha e à Inglaterra, não era interrompido.

Como refere Lydie Arbogast $(2016,5)$, apesar da aplicação de tecnologias no controlo e regulação dos migrantes (satélites, drones ou câmaras de infravermelhos), “(...) Apart from these legal and operational mechanisms, real physical barriers such as walls, fences, barbed wire and watchtowers are springing up along the borders of the Schengen area, accompanied by a range of 
security measures of ever increasing sophistication - drones, satellites, heartbeat detectors, infrared cameras, etc. - to keep migrants out. Restrictive and security policies have failed to dissuade prospective migrants, and merely oblige them to change course, making longer, more costly, more risky journeys, sometimes putting their lives in danger".

Nestes territórios de tensão e de espera, confrontam-se as novas tecnologias com os velhos métodos de contenção - o arame farpado, uma inovação do final do século XIX, nos EUA, para proteção da propriedade privada agrícola dos colonos europeus, face aos riscos de assédio por parte das populações nómadas autóctones e dos avanços dos criadores de gado (HARFORD, 2018).

Com estes muros, mais ou menos efémeros, multiplicaram-se os espaços e os tempos de paragem e definiram-se territórios de espera. Estes acontecem na perspetiva dos grupos humanos que viam o seu percurso interrompido, aguardando oportunidade para seguir viagem. Mas, esta espacio-temporalidade de espera também ocorre no território que se define na outra margem, no outro lado da barreira. Enquanto linha de tensão entre quem desafia um poder (migrantes em espera) e quem o exerce (as autoridades policiais), também dos lado das forças de segurança se define um território de espera, vigiando e aguardando as investidas do aglomerado humano que pretende seguir caminho.

Leia-se, a este propósito, Reece Jones (2017, 13-14): "Spain began to construct fences and barricades on the boundaries of Melilla in 1993, and they have been redesigned and expanded in multiple times. The current wall complex is made of three fences, the tallest of which is six meters (...), all heavily reinforced to prevent them from being knocked down by a truck. The Spanish Guardia Civil, in older white trucks with green doors, patrol the roads along the edge of the fences, looking for anything out of place" (o destaque é nosso).

Com efeito, existe uma cartografia heterogénea de territórios de espera e de geografias de potencial (e efetiva) conflitualidade definidas por pontos, linhas ou áreas, nas fronteiras externas da União Europeia, mas também no interior do próprio espaço Schengen. Nesta realidade geográfica que se (re) estruturou e, nalguns casos, se reforçou a partir do afluxo de potenciais refugiados através do Mediterrâneo no verão de 2015, a perenidade dos muros de demarcação é também muito diversificada. Em muitos casos, trata-se de uma geografia flexível, ou líquida, como diria Bauman (2007), de duração limitada, mas com efeitos sistémicos. Nestes territórios incertos, como se verá no caso do denominado Jungle, em Calais (França), esta espacialidade precária representará um sistema global contraditório, social e politicamente fragmentado, que coexiste justapondo diferentes velocidades.

\section{The Jungle (a Selva) - território de espera em Calais, no norte de França. $O$ documentário "Calais, the end of the jungle", de Dan Reed (2017)}

Um dos territórios de espera com mais visibilidade na Europa, no período de maior afluxo de migrantes e potenciais refugiados durante o verão de 2015, formou-se em Calais, no norte de França. A efemeridade do lugar dá valor aos registos documentais, que deixaram imagens e sons daquela 
realidade geográfica. Como qualquer obra cinematográfica, o documentário de Dan Reed, editado em 2017, não é um retrato mas sim uma representação. As narrativas, os planos, a fotografia, a condução geral daquele trabalho audiovisual são, com naturalidade, elementos filtrados pelos seus autores. No entanto, esse facto não condiciona o realismo desta obra de Reed nem a sua relevância enquanto instrumento de aproximação a uma geografia complexa.

Esta incursão no filme de Dan Reed é uma viagem pelo Jungle, uma toponímia improvisada que, simbolicamente, nos remete para um retrocesso civilizacional que feriu a Europa dos valores e dos Direitos Humanos no interior do seu próprio território. Com a duração aproximada de uma hora, "Calais, the end of the Jungle", acompanha aquele campo improvisado de migrantes entre o momento, após o verão de 2015, da sua máxima ocupação (que refere aproximar-se dos 10 mil migrantes) e o seu desmantelamento no início de 2017.

Localizado na proximidade do porto de ferries que seguem para o Reino Unido, confinando com uma via rápida que dá acesso a essa área portuária e não muito distante do terminal do Eurotúnel, o (campo) Jungle é um território de exclusão encravado nos interstícios geográficos de vias e nós de mobilidade rápida nas quais assenta a ligação de França (e da Europa continental), com a Inglaterra.

Nesse sentido, este microterritório murado por vedações reforçadas por arame farpado, confina com os nós e as redes da globalização, sem ao mesmo tempo fazer parte destas. Neste mundo fragmentado, organizado em diferentes velocidades e estruturado por efeitos de atrito muito diferenciado, a coexistência euclidiana (e a proximidade física) não implica contacto, fluidez e liberdade de movimentos. As distâncias social, cultural, económica e política são grandes e condicionadas pelo medo. No documentário, Reed entrevista alguns dos responsáveis pela gestão territorial de Calais. Estes expressam temores e receios: a cidade, com cerca de 70 mil habitantes, poderia comportar 1500 a 2000 migrantes, mas não consegue acondicionar os valores e as densidades verificados no Jungle, ainda que não existam certezas absolutas sobre a real dimensão demográfica deste espaço geográfico.

As câmaras de Reed mostram-nos um campo que não é uniforme. Este território de espera é um espaço de múltiplos atores e as relações de poder entre cada um destes protagonistas são assimétricas. Esta é uma geografia de deslocados, migrantes e potenciais refugiados, sobretudo masculinos - as incertezas resultam da indefinição de estatuto, uma das componentes da espera que, no tempo e no espaço, vai afetando a condição destas populações.

Dan Reed não o refere de modo explícito, mas o campo está dividido por grupos étnicos que refletem os conflitos geopolíticos, com uma diversidade que, seguindo Hassina Mechaï (2015) espelha as crises geopolíticas contemporâneas - entre outros, aqui encontram-se deslocados sudaneses e do Darfur, em resultado da guerra no Sudão do Sul e da fuga ao regime de Omar alBashir. Também aqui se fixaram afegãos que há muito foram escapando do antigo regime repressivo dos talibans, da intervenção externa, das faltas de garantias do país na defesa dos direitos humanos e na promoção do bem-estar, mesmo sob o governo das novas autoridades. Para além destes, viamse mulheres da Eritreia, com idades inferiores aos 17 anos - fugiam do regime político e escapavam ao encarceramento num serviço militar obrigatório compulsivo e de prazos indefinidos. Para além 
destes, também lá estão os sírios e os líbios, como testemunhos do colapso e dos conflitos nestes dois territórios políticos.

Neste Jungle de diversidade étnica e cultural, o espaço geográfico vai-se estruturando, ritmado, entre outros registos sonoros, pela voz do muezim que chama os fiéis para a oração. No Jungle criaram-se espaços religiosos e pequenas mesquitas improvisadas, mas no skyline filmado por Dan Reed também se veem torres com símbolos cristãos. Neste lugar efémero, existem espaços de pernoita e residência, bazares, armazéns e mercados nos quais se disponibilizam produtos doados.

Mas este espaço geográfico é também o território das autoridades, dos agentes de segurança e das forças francesas antimotim, que entram no campo para demonstrar o seu poder e disciplinar os imigrantes. O Jungle é também o espaço no qual se inscrevem os criminosos organizados em rede. De acordo com este trabalho de Reed, no terreno estariam sempre 10 equipas de passadores, cada uma com 2 ou 3 elementos e uma carrinha. Em cada noite, cada grupo conseguiria fazer passar 15 clandestinos. A uma média de 3 mil euros cobrados por cada um desses deslocados em direção a Inglaterra, esta atividade criminosa sustenta uma economia informal elevada.

Para além destes, o Jungle é o território dos voluntários, alguns vindos da Inglaterra, mas também de outros países europeus e não só. Perante o triângulo migrante-passador-polícia, na ótica deste documentário de Reed, o contacto com as organizações não governamentais, e com as pessoas que as dinamizam, acaba por ser uma experiência de relações humanas (e de humanidade) num contexto extremo no qual a desumanização é a regra.

Naquele momento considerado o maior slum de África, no Jungle a precariedade é grande. Trata-se de um território de tendas, que depois evoluiu, com a ajuda humanitária, para construções frágeis de madeira. Faltam serviços básicos, o acesso à alimentação está organizado por filas que protelam as refeições. Num território no qual o tempo se prolonga, fazem-se pausas e há uma espera para alcançar os bens essenciais.

Neste confinamento anti-idílico, as pressões e os conflitos são frequentes, por vezes entre as diferentes comunidades dos próprios imigrantes, entre sudaneses e afegãos, por exemplo. Dan Reed recolhe alguns testemunhos oficiais: no Jungle terão sido usadas, por parte da polícia, mais de 30 mil bombas de gás lacrimogénio.

Contudo, este será sempre um contexto contraditório de dilemas morais. Para algumas autoridades francesas entrevistadas, como se pode negar o acesso destes migrantes ao desejado destino final (a Inglaterra, a escassos $20 \mathrm{~km}$ )? Tratam-se de deslocados que viajaram por percursos de 2 ou 3 mil km, durante várias semanas, ou meses, vivendo trajetos difíceis, ultrapassando barreiras ineficazes levantadas na retaguarda, a montante.

Este território de espera está marcado por outro dilema: como justificar, perante a opinião pública de França, que as autoridades nacionais estejam a defender a fronteira do Reino Unido e, de modo indireto, a estimular a fixação destes migrantes no território francês?

Neste espaço geográfico, são muitas as pressões sobre os muros de confinamento e evidentes as relações de poder ali estabelecidas. O próprio grupo de migrantes não é homogéneo. Os deslocados mais pobres, de origem subsaariana, como não conseguem pagar uma passagem 
clandestina nem ter acesso às geografias subterrâneas das redes criminosas organizadas, acabam por deambular pelo campo e pelas suas intermediações.

Para estes migrantes mais pobres, o acesso ao objetivo desejado - 0 atravessamento do Canal da Mancha, faz-se por tentativas. Procura-se a entrada clandestina no Eurotúnel ou, como se enfatiza no trabalho de Dan Reed, tenta-se o acesso forçado aos veículos pesados que percorrem a via rápida em direção ao porto marítimo.

Entrar nos camiões em movimento é impossível. Por isso, levantam-se barragens ao movimento (e, de certo modo, novos territórios de paragem e de espera), colocando obstáculos na estrada para obrigar os condutores a parar. Troncos, postes, colchões incendiados e botijas de gás, são muitas as estratégias para fazer parar os camionistas, simultaneamente em diferentes pontos da estrada, para distrair e dividir a atenção das autoridades. O conflito é aqui elevado. Este é um território de medo: alguns condutores sofreram agressões e receiam ser multados à entrada de Inglaterra, caso transportem passageiros clandestinos. Algumas dezenas de imigrantes morreram na tentativa de entrar e esconder-se nos veículos. Em cada ataque nesses engarrafamentos forjados, avançam 200 ou 300 deslocados, sobretudo africanos. Segundo informações recolhidas por Reed, por noite ocorreriam 20 a 25 bloqueios, demonstrando, pelo menos, que a população que espera não o faz numa atitude passiva.

Estes migrantes, os mais saudáveis e bem preparados sob o ponto de vista físico entre aqueles que terão atravessado o Mediterrâneo, tentam contornar as barreiras de acesso e entrar nos canais de velocidade da globalização. Neste Jungle de espera, estas populações precárias procuram tirar partido de um poder: o da interrupção de uma via rápida e de trânsito fluído, que liga duas cidades do Arquipélago Metropolitano Mundial - Londres e Paris.

Como referido, Dan Reed acompanha a fase de desintegração deste espaço geográfico efémero e transitório. Esse desmantelamento, a avaliar pelas palavras de entrevistados, fez-se em pouco tempo. Demasiado rápido para um processo que implicaria a identificação dos migrantes e a sua deslocação para centros de acolhimentos legais noutras cidades francesas, nos quais encontrariam a face mais humana de França e boas oportunidades de legalização (segundo testemunhas oficiais entrevistadas por Dan Reed).

Contudo, assim não ocorreu. Estes aglomerados de exclusão em movimento, que se vão fixando e deslocando em ciclos sucessivos de des-reterritorialização (Haesbaert, 2004), não partem do campo Jungle sem antes reagirem, provocando desacatos e ateando incêndios. Este tornou-se um território de difusão caótica de parte dos deslocados que ali se tinham fixado. A câmara de Dan Reed acompanha-os até Paris e redescobre-os nas praças, nos passeios e nos espaços devolutos debaixo de viadutos urbanos. Num dos planos, associando estas geografias deambulantes à política, filma-se um cartaz de Marine Le Pen e da Frente Nacional.

Apesar da destruição do campo, com uma paisagem de caos que se assemelharia a uma warscape, alguns destes migrantes acabaram por regressar a Calais, mas o Jungle não se repetiu. Por parte dos deslocados, era preciso insistir no acesso a Inglaterra, onde eram aguardados por familiares. 
O documentário termina com um testemunho, o primeiro refugiado ouvido no filme de Dan Reed: um eritreu que chegou à Europa através da Itália e que, depois de muitas tentativas em Calais, acabou por alcançar o Reino Unido. Fugido de abusos e da exploração humana, na Eritreia estava condenado a um serviço militar obrigatório permanente, que the cativaria toda a vida. O Reino Unido era um objetivo: pela língua mas também pela vontade de continuar a estudar e frequentar uma universidade inglesa. Esteve 2 meses em Calais, numa situação de espera, sempre tentando uma oportunidade. Apesar do cansaço, renasceu assim que entrou no Canal da Mancha.

Para uma voluntária europeia do Jungle, o tema dos refugiados será sempre um problema. Este fluxo não terminará. Como disse perante as câmaras de Reed, tal como acontece com a água, este movimento trava-se aqui mas irá aparecer noutro lugar. Porventura, estes deslocados poderão regressar ao norte de França. Como refere Jessica Reinish $(2015,7)$, "Whether or not they succeed in their attempts to come to Europe is still determined by their luck, financial resources, family connections and ability to manoeuvre through the paper world of asylum and immigration policies. Many hundreds of thousands will continue to embark on dangerous and humiliating journeys in search of a better life, one without the daily threat of war, hunger, disease, or poverty, and many of them will continue to die in the process. A few of them might end up in Calais".

\section{Notas finais}

O conceito de território de espera permite realizar uma viagem por diferentes contextos espaciais e temporais. A referida espera pode ser uma estratégia defensiva de mitigação de riscos. Contudo, em múltiplas circunstâncias, a interrupção dos fluxos e o confinamento de populações em espaços reduzidos, criam contextos de potencial tensão, conflitualidade e violência. As migrações, com um foco muito particular na Europa que atraiu uma procura elevada de deslocados, em especial no verão de 2015, promovem múltiplos lugares de espera e de interrupção do movimento.

Como a mobilidade espacial não é livre, como o efeito de atrito para a deslocação das populações não desapareceu, os candidatos ao estatuto de refugiado que se dirigiram para a Europa no culminar da crise ocorrida em espaços geográficos com a Líbia e a Síria, foram sendo progressivamente confrontado por múltiplas barreiras. Estes muros desaceleravam o movimento destes migrantes, fazendo-os, por vezes, parar em espaços confinados.

Um dos exemplos foi explorado neste trabalho. A Selva (Jungle, no original) foi um campo de aglomeração de potenciais refugiados, localizado nas portas entre França e Inglaterra, na margem sul do Canal da Mancha (Calais). Foi também um território de espera efémero, desmantelado logo nos inícios de 2017. Ainda assim, tratou-se de um espaço geográfico de encontro (e, por vezes, confronto) entre diferentes atores: os migrantes (muito divididos por etnias, nacionalidades, percursos e capital disponível); as redes de crime organizado; as forças de segurança e as autoridades francesas; e, por fim, os voluntários e as Organizações Não Governamentais.

Em Calais, este campo de contenção de migrantes existe entre os eixos e os nós da globalização, que atravessam o Canal da Mancha e unem França e a Inglaterra. Estas vias rápidas parecem fluir sem notar a presença destes deslocados. 
No entanto, a coexistência pacífica entre a veloz geografia da compressão do espaço-tempo e as territorialidades precárias das populações em espera, é uma ilusão. O choque deu-se no Eurotúnel e na via rápida que liga Calais, e o resto do país, ao porto de ferries e, daqui, a Inglaterra e a uma cidade global - Londres. Os candidatos a refugiados boicotaram a estrada, criando também nesta um território de espera (e confronto), entre os residentes no Jungle e os camionistas obrigados a abrandar e a estabilizar. Esta paragem abria uma possibilidade: a entrada nos veículos pesados poderia ser uma porta de entrada na desejada Inglaterra.

Os episódios de tensão, e o ambiente de conflitualidade entre estes diferentes atores, ocorreram em Calais mas também em Lampedusa, Lesbos, Atenas, Roma, Paris, ou nos campos de detenção da Líbia, às portas do continente europeu. A Carta dos Direitos Fundamentais da União Europeia, na qual se promove, no seu artigo 1ำ, o respeito e a proteção da inviolabilidade da dignidade do ser humano, obriga a que se foquem estes territórios de espera como uma das prioridades dos Estados europeus democráticos e signatários desses princípios.

\section{Bibliografia}

AGIER, M. (dir.) (2014). Un monde des camps. Paris: La Découverte.

ARBOGAST, L. (2016). Migrant detention in the European Union: a thriving business. Outsourcing and privatization of migrant detention. Brussels: Migreurop.

BARATA, C. (2018). A revolta dos Coletes Amarelos ameaça bloquear Paris no sábado. Público, edição de 20 de novembro, 26.

BAUMAN, Z. (2007). Liquid Times: Living in an Age of Uncertainty. Cambridge: Polity Press.

DOWDALL, A.; HORNE, J. (ed.) (2018). Civilians Under Siege from Sarajevo to Troy. London: Palgrave Macmillan.

ESI- EUROPEAN STABILITY INICIATIVE (2017). The refugee crisis through statistics. A compilation for politicians, journalists and other concerned citizens. Berlim.

HAESBAERT, R. (2014). O mito da desterritorialização. Rio de Janeiro: Bertrand Brasil.

HARFORD, T. (2018). 50 coisas que mudaram o mundo. Lisboa: Objectiva.

HASS, A. (2005). Beber o mar em Gaza. Dias e noites de uma terra cercada. Lisboa: Caminho.

JAUHIAINEN, Jussi (2017). Asylum seekers in Lesvos, Greece, 2016-2017. Turku: Turun yliopisto ja geologian laitos maantiede.

JONES, M. (2008). Leningrad. State of siege. London: John Murray.

KAJJA, Kamal (2009). Al-Jazeera, phénomène ou leurre?. Hérodote, n¹33, 152-163.

KOTSIOU, A.; MICHALAKI, V.; ANAGNOSTOPOULOU, H. N. (2017). Devastating epidemics in recent ages greek populations. Acta Med Hist Adriat, 15(2), 283-290.

MACEK, Ivana (2009). Sarajevo under siege. Anthropology in wartime. Philadelphia: University of Pennsylvania Press.

MURRAY, D. (2018). A estranha morte da Europa. Imigração, identidade, religião. Porto Salvo: Edições Desassossego.

MUSSET, A. (2015). De los lugares de espera a los territorios de la espera. ¿Una nueva dimensión de la geografía social?. Documents d'Anàlisi Geogràfica, vol. 61/2, 305-324. 
PALLISTER-WILKINS, P. (2018). Hotspots and the geographies of humanitarianism. Environment and Planning D: Society and Space, 1-18.

RAFFESTIN, C. (1980). Pour une géographie du pouvoir. Paris: Librairies Techniques (LITEC).

REINISCH, J. (2015). 'Forever Temporary': Migrants in Calais, Then and Now. The Political Quarterly, 1-8.

THABET, Abdel Aziz Mousa (2017). Palestinian Children: Victims of Decades of Violence and Trauma. JOJ Nursing \& Health Care, (2)3, 1-8.

TINTI, P.; REITANO, T. (2018). Migrant, refugee, smuggler, savior. London: Hurst \& Company.

TOMCZYK, A. (2018). Georgia's separatist regions at a standstill. New Eastern Europe, nํ-4 (XXXII), 53-59.

TUMARKIN, M. (2005). Traumascapes: The Power and Fate of Places Transformed by Tragedy. Melbourne: Melbourne University Press.

VELOSO, A. (2009). Caramulo. Ascensão e queda de uma estância de tuberculosos. Lisboa: By the Book.

VIDAL, L.; MUSSET, A. (dir.) (2015). Les territoires de l'attente. Migrations et mobilités dans les Amériques (XIXe-XXIe siècle). Rennes: Presses Universitaires de Rennes.

WAAL, T. de (2018). Uncertain territory. The strange life and curious sustainability of de facto states. New Eastern Europe, ํ3-4 (XXXII), 7-14.

WACHTER, A. (2018). 'This Did not Happen': Survivors of the Siege of Leningrad (1941-1944) and the 'Truth About the Blockade'. In Alex Dowdall and John Horne (ed.), Under Siege from Sarajevo to Troy. London: Palgrave Macmillan, 37-60. 